CZASOPISMO INŻYNIERII LADOWEJ, ŚRODOWISKA I ARCHITEKTURY JOURNAL OF CIVIL ENGINEERING, ENVIRONMENT AND ARCHITECTURE

JCEEA, t. XXXII, z. 62 (3/I/15), lipiec-wrzesień 2015, s. 243-252

Jadwiga KRÓLIKOWSKA ${ }^{1}$

Marek KUBALA ${ }^{2}$

\title{
ANALIZA PROBLEMÓW PRAKTYCZNEGO ZASTOSOWANIA METODY DEKOMPOZYCJI I EKWIWALENTOWANIA
}

\begin{abstract}
W pracy przedstawiono metodę dekompozycji i ekwiwalentowania (MDE), zaproponowaną przez Ju. A. Jermolina i M. I. Alieksjejewa do obliczania parametrów niezawodnościowych sieci kanalizacyjnej, zdecydowanie prostszą i mniej uciążliwą w stosunku np. do metody przeglądu zupełnego, metody wzorów analitycznych, metody częstości uszkodzeń czy metody grafów. Analizując metodę przedstawioną w [1] autorzy przyjęli założenie, że tylko kanały będące krawędziami grafu zakończonymi liśćmi, czyli kanały zewnętrzne sieci, mają niezerowy wydatek, co stanowi ograniczenie jej praktycznego zastosowania. Drugą kwestią, mocno ograniczającym praktyczne zastosowanie MDE, jest niejawne, aczkolwiek jasno wynikające z samego algorytmu dekompozycji, założenie, że sieć jest drzewem binarnym. Takie założenie wyklucza przypadki, kiedy węzeł łączy więcej niż dwa kanały dopływające. Celem niniejszej pracy było przedstawienie rozwiązań tych problemów (ograniczeń).
\end{abstract}

Słowa kluczowe: niezawodność, sieci kanalizacyjne, graf, dekompozycja, ekwiwalentowanie, awaryjność

\section{Wprowadzenie}

Awarie w obrębie systemów kanalizacyjnych, zwłaszcza sieci kanalizacyjnych grawitacyjnych mogą wywołać sytuacje niebezpieczne a nawet zdarzenia katastroficzne, niekorzystnie oddziałując na środowisko gruntowo-wodne w otoczeniu kanału i gospodarkę przestrzenną. W analizach niezawodnościowych należy więc utratę zdolności funkcjonowania systemu bezwzględnie łączyć z jego skutkami $[2,10]$. Do oceny niezawodności funkcjonowania systemów kanalizacyjnych, składających się w zasadzie z elementów odnawialnych, zastosowanie mają miary, które opisują poszczególne cechy systemów, a mianowicie $[2,7,8]$ :

\footnotetext{
${ }^{1}$ Autor do korespondencji: Jadwiga Królikowska, Politechnika Krakowska, ul. Warszawska 24, 31-155 Kraków, tel. 12628 2871, jkapcia@ vistula.wis.pk.edu.pl

${ }^{2}$ Marek Kubala, Politechnika Krakowska
} 
- miary bezawaryjności charakteryzujące zdolność systemu do zachowania sprawności podczas wykonywania zadania (średni czas pracy między uszkodzeniami Tp, parametr strumienia uszkodzeń $\lambda$, częstość uszkodzeń f),

- miary naprawialności charakteryzujące podatność obiektu na wykonanie naprawy; naprawialność charakteryzuje nie tylko uszkodzony element, ale również sprawność techniczno-organizacyjną brygad naprawczych całego systemu obsługi awaryjnej, obejmującego zaopatrzenie w części zamienne, sprzęt, materiały itp. (średni czas naprawy Tn, intensywność odnowy $\mu$ ) oraz

- miarę gotowości charakteryzującą wpływ uszkodzeń (niesprawności) i związanej z nim odnowy na bezawaryjną realizację zadań przez obiekt; charakterystyki te opisują niezawodność obiektu kanalizacyjnego uwzględniając jednocześnie co najmniej dwie cechy niezawodności (wskaźnik gotowości K).

Uwzględniając bardzo złożoną strukturę typu „drzewo”, czyli strukturę hierarchiczną, z której wynika, że wszystkie ścieki z miejsca ich powstania są dostarczane do oczyszczalni ścieków po jedynej możliwej drodze, poprzez ściśle określoną kolejność odcinków (kanałów bocznych i kolektorów), czyli jest ukierunkowany acykliczny graf literatura wskazuje na możliwość zastosowania do szacowania miar niezawodności takich metod analitycznych jak: metoda przeglądu zupełnego, metoda wzorów analitycznych, metoda częstości uszkodzeń czy metoda grafów $[3,4,5,11]$. Każda z tych metod charakteryzuje się właściwościami aplikacyjnymi w ocenie niezawodnościowej omawianych systemów. Różnią się obszarem (zakresem) możliwości; żadna z nich nie jest metodą uniwersalną. W przypadku podsystemu usuwania ścieków ma się do czynienia zarówno z obiektami o strukturze prostej jak i strukturze złożonej. Struktury proste odzwierciedlają obiekty występujące na sieci takie, jak np. pompownia ścieków, syfon kanalizacyjny, natomiast sama sieć (układ przewodów kanalizacyjnych), jak już wspomniano, tworzy strukturę złożoną. To właśnie rodzaj struktury decyduje w znacznej mierze o wyborze metody oceny niezawodności syste$\mathrm{mu}$ i z uwagi na strukturę sieci grawitacyjnej są dość kłopotliwe.

Konkurencyjną do wymienionych metod jest metoda dekompozycji i ekwiwalentowania, (dalej MDE), zaproponowana przez Ju. A. Jermolina i M. I. Alieksjejewa [1] do obliczania parametrów niezawodnościowych sieci kanalizacyjnej, zdecydowanie prostsza i mniej uciążliwą. Możliwości aplikacyjne metody można znaleźć w literaturze $[1,6,9]$.

Celem niniejszej pracy jest przedstawienie rozwiązań problemów wynikających z praktycznego jej zastosowania.

\section{Opis metody}

Metoda dekompozycji i ekwiwalentowania (MDE) wychodzi z założenia, że sieć kanalizacji grawitacyjnej, ze względu na jej topologię, można traktować jako graf typu drzewo, którego krawędziami są odcinki kanałów, a wierzchołka- 
$m i$ węzły sieci (rys. 1.). Dodatkowo, ze względu na geometrię sieci, można stwierdzić, że jest to drzewo ukorzenione, którego korzeniem jest odbiornik na końcu sieci. Na rys. 1. jest to węzeł nr w0.

Na takim drzewie można określić relacje hierarchii, poczynając od wyróżnionego węzła (korzenia). Spośród dwóch węzłów połączonych krawędzią bliższy korzeniowi nazywamy ojcem (bądź rodzicem), a dalszy dzieckiem (bądź synem). Jak łatwo zauważyć, relacja ta jest tożsama z kierunkiem spływu ścieków, jedynie jej zwrot jest przeciwny. Dzieckiem będzie węzeł, w którym kanał bierze początek, a rodzicem węzeł, na którym kanał się kończy.

Wierzchołki drzewa, które nie mają potomków, nazywamy liśćmi. W kategoriach geometrii sieci grawitacyjnej są to węzły, które posiadają jedynie kanał odpływowy i do których nie dochodzą żadne kanały dopływowe. Na rys. 1. są to węzły w4, w14, w15, w9, w10, w11, w12 i w13.

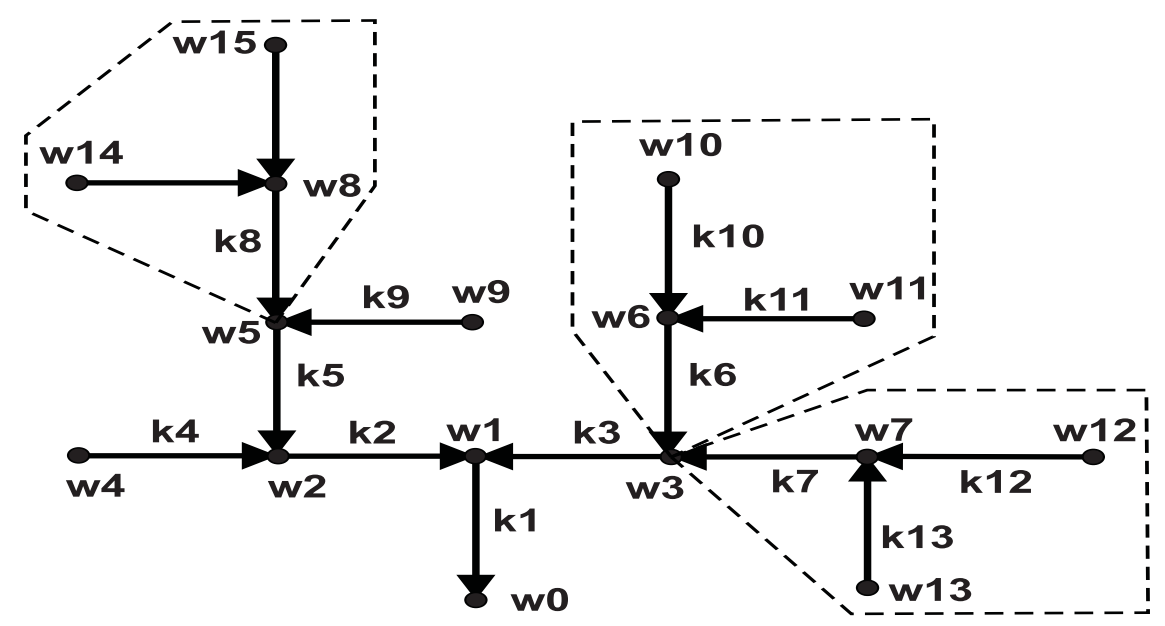

Rys. 1. Przykładowa sieć kanalizacyjna, jako graf typu drzewo z zaznaczonymi gałęziami

Fig. 1. Sewage network, as a tree type graph with marked branches

Jermolin i Alieksjejew, autorzy MDE, zakładają również implicite, że jest to regularne drzewo binarne, co w kategoriach struktury sieci oznacza, że w każdym jej węźle wewnętrznym łączą się dwa (i tylko dwa!) kanały dopływowe, a wychodzi z niego jeden kanał odpływowy.

Najdalej idącym jednak założeniem, mającym wpływ na praktyczne zastosowanie tej metody, jest przyjęcie zasady, iż jedynie kanały będące w grafie krawędziami zakończonymi liśćmi posiadają wydatek $q$ różny od zera. Przyjmując w tej pracy zasadę numerowania krawędzi grafu (kanałów) numerami węzłów potomnych, możemy je określić jako kanały nr k4, k14, k15, k9, k10, k11, k12 i k13.

W strukturze grafu można zatem wyróżnić Y-kształtne struktury składające się z trzech krawędzi, z których dwie, połączone w węźle macierzystym, zakończone są liśćmi. Na rys. 1. struktury te zaznaczone są obrysami. 
Struktury zastępujemy jednym kanałem ekwiwalentnym (rys. 2.), o niezerowym wydatku $q$. W kolejnym etapie dekompozycji czynność tę powtarzamy aż do zastąpienia całej sieci pojedynczym kanałem.

a)

b)
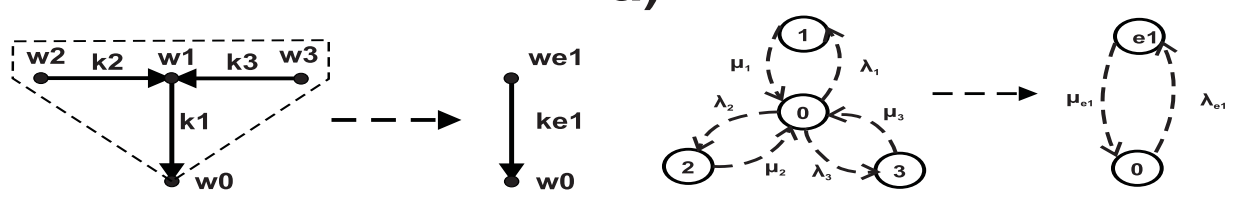

Rys. 2. Schematyczne przedstawienie zastąpienia struktury Y-kształtnej jednym kanałem ekwiwalentnym (rys. 2a) oraz odpowiadające temu zabiegowi grafy stanów (rys. 2b)

Fig. 2. Replacement of a Y-shaped structure with one equivalent channel (Fig. 2a) and corresponding state graphs (Fig. 2b)

Przyjmując założenie, że prawdopodobieństwo awarii dwóch lub więcej kanałów jednocześnie jest znacząco mniejsze od prawdopodobieństwa awarii pojedynczego kanału, stan struktury Y-kształtnej można przedstawić jako sumę czterech stanów: 0 - wszystkie trzy kanały są sprawne, 1 - kanał k1 jest niesprawny, 2 - kanał k2 jest niesprawny i 3 - kanał k3 jest niesprawny. Przejścia pomiędzy tymi stanami następują z odpowiednią intensywnością uszkodzeń $\left(\lambda_{1}\right.$, $\left.\lambda_{2}, \lambda_{3}\right)$ i odnowy $\left(\mu_{1}, \mu_{2}, \mu_{3}\right)$. Określając dla każdego kanału bezwymiarowy parametr $\gamma$, równy ilorazowi intensywności uszkodzeń $\lambda$ i odnowy $\mu$, możemy określić prawdopodobieństwa $p_{0}, p_{1}, p_{2}$ i $p_{3}$ odpowiednio dla stanów $0,1,2$, i 3 : prawdopodobieństwa $p_{0}, p_{1}, p_{2}$ i $p_{3}$ odpowiednio dla stanów $0,1,2$, i 3 :

$$
\begin{aligned}
& p_{0}=\frac{1}{1+\gamma_{1}+\gamma_{2}+\gamma_{3}} \\
& p_{1}=\frac{\gamma_{1}}{1+\gamma_{1}+\gamma_{2}+\gamma_{3}} \\
& p_{2}=\frac{\gamma_{2}}{1+\gamma_{1}+\gamma_{2}+\gamma_{3}} \\
& p_{3}=\frac{\gamma_{3}}{1+\gamma_{1}+\gamma_{2}+\gamma_{3}}
\end{aligned}
$$

Mając na uwadze założenie MDE, że średni wydatek kanału $\mathrm{k} 1, q_{1}$, jest równy 0 , możemy określić prawdopodobieństwa nieodprowadzenia do odbiornika określonej ilości ścieków w określonym czasie $T$ :

$$
p_{0} \rightarrow 0 ; \quad p_{1} \rightarrow\left(q_{2}+q_{3}\right) T ; \quad p_{2} \rightarrow q_{2} T ; \quad p_{3} \rightarrow q_{3} T
$$


co bezpośrednio prowadzi do obliczenia wartości oczekiwanej nieodprowadzonych w czasie $T$ ścieków z tej części kanalizacji:

$$
Q=p_{3} q_{3} T+p_{2} q_{2} T+p_{1}\left(q_{2}+q_{3}\right) T
$$

Z układu równań (1), otrzymujemy ostatecznie:

$$
Q=\frac{\left(\gamma_{2}+\gamma_{1}\right) q_{2}+\left(\gamma_{3}+\gamma_{1}\right) q_{3}}{1+\gamma_{1}+\gamma_{2}+\gamma_{3}} T
$$

Podobne rozumowanie możemy przyjąć dla kanału ekwiwalentnego, dla którego określamy tylko dwa stany: 0 - kanał jest sprawny oraz e1 - kanał jest niesprawny. Przyjmując dla tego kanału oznaczenia strumieni intensywności uszkodzeń i odnowy jako $\lambda_{\mathrm{e} 1}$ i $\mu_{\mathrm{e} 1}$ oraz odpowiadający im bezwymiarowy parametr $\gamma_{\mathrm{el}}$, możemy określić prawdopodobieństwa stanów jako:

$$
\begin{aligned}
& p_{0}=\frac{1}{1+\gamma_{e 1}} \\
& p_{e 1}=\frac{\gamma_{e 1}}{1+\gamma_{e 1}}
\end{aligned}
$$

oraz prawdopodobieństwa nieodprowadzenia w czasie $T$ odpowiednich ilości ścieków do odbiornika:

$$
p_{0} \rightarrow 0 ; \quad p_{e 1} \rightarrow\left(q_{2}+q_{3}\right) T
$$

i wartość oczekiwaną nieodprowadzonych w czasie $T$ ścieków:

$$
Q_{e}=p_{e 1}\left(q_{2}+q_{3}\right) T
$$

lub

$$
Q_{e}=\frac{\gamma_{e 1}}{1+\gamma_{e 1}}\left(q_{2}+q_{3}\right) T
$$

Przyrównując do siebie wartości oczekiwane nieodprowadzonych ścieków dla struktury Y-kształtnej i kanału ekwiwalentnego, otrzymujemy wartość parametru $\gamma_{\mathrm{e} 1}$ :

$$
\gamma_{e 1}=\frac{\left(\gamma_{2}+\gamma_{1}\right) q_{2}+\left(\gamma_{3}+\gamma_{1}\right) q_{3}}{\left(1+\gamma_{3}\right) q_{2}+\left(1+\gamma_{2}\right) q_{3}}
$$


W większości przypadków parametry $\gamma$ dla poszczególnych kanałów są dużo mniejsze od 1, tak więc powyższy wzór upraszcza się do postaci:

$$
\gamma_{e 1} \approx \frac{\left(\gamma_{2}+\gamma_{1}\right) q_{2}+\left(\gamma_{3}+\gamma_{1}\right) q_{3}}{q_{2}+q_{3}}
$$

Warto również zauważyć, że w przybliżeniu małych wartości parametru $\gamma$ mianownik we wzorze (8) zmierza do 1 . W takim wypadku wyraźny staje się sens fizyczny tego parametru. Reprezentuje on względną część wprowadzonych do kanału ścieków, która, wskutek uszkodzeń, w zadanym czasie $T$ nie została $\mathrm{z}$ niego odprowadzona.

\section{Problemy praktycznego zastosowania MDE i propozycje ich rozwiązania}

Największy problem praktycznego zastosowania MDE stanowi założenie, że tylko kanały będące krawędziami grafu zakończonymi liśćmi, czyli kanały zewnętrzne sieci, mają niezerowy wydatek. Wadę tę można by w prosty sposób wyeliminować, gdybyśmy przyjęli, że liśćmi grafu są wszystkie przyłącza. Rozwiązanie to jest jednak niepraktyczne, gdyż nie sposób określić w praktyce parametry $\lambda$ oraz $\mu$ dla wszystkich przyłączy. Poza tym taki zabieg nadmiernie rozbudowałby drzewo grafu, co uczyniłoby całą metodę niepraktyczną. Należy zatem zrezygnować z powyższego założenia, przyjmując, że również $q_{1}$ jest niezerowe, i spróbować określić wartość $\gamma_{\mathrm{el}}$.

Idąc tropem rozumowania autorów MDE oznaczamy prawdopodobieństwa nieodprowadzenia do odbiornika określonej ilości ścieków w określonym czasie $T$ w następujący sposób:

$$
p_{0} \rightarrow 0 ; \quad p_{1} \rightarrow\left(q_{1}+q_{2}+q_{3}\right) T ; \quad p_{2} \rightarrow q_{2} T ; \quad p_{3} \rightarrow q_{3} T
$$

oraz wartość oczekiwaną nieodprowadzonych w czasie $T$ ścieków z tej części kanalizacji:

$$
Q=p_{2} q_{2} T+p_{3} q_{3} T+p_{1}\left(q_{1}+q_{2}+q_{3}\right) T
$$

co wobec (1) prowadzi do zależności:

$$
Q=\frac{\left(\gamma_{2}+\gamma_{1}\right) q_{2}+\left(\gamma_{3}+\gamma_{1}\right) q_{3}+\gamma_{1} q_{1}}{1+\gamma_{1}+\gamma_{2}+\gamma_{3}} T
$$

Dla kanału ekwiwalentnego otrzymujemy następujący zestaw prawdopodobieństw i odpowiadających im nieodprowadzonych w czasie $T$ ilości ścieków:

$$
p_{0} \rightarrow 0 ; \quad p_{e 1} \rightarrow\left(q_{1}+q_{2}+q_{3}\right) T
$$


oraz wartość oczekiwaną nieodprowadzonych w czasie $T$ ścieków:

$$
Q_{e}=p_{e 1}\left(q_{1}+q_{2}+q_{3}\right) T
$$

Ponownie przyrównując do siebie $Q$ i $Q_{e}$ otrzymujemy wyrażenie na wartość $\gamma_{\mathrm{e} 1}$ :

$$
\gamma_{e 1}=\frac{\left(\gamma_{2}+\gamma_{1}\right) q_{2}+\left(\gamma_{3}+\gamma_{1}\right) q_{3}+\gamma_{1} q_{1}}{\left(1+\gamma_{3}\right) q_{2}+\left(1+\gamma_{2}\right) q_{3}+\left(1+\gamma_{2}+\gamma_{3}\right) q_{1}}
$$

Jeżeli, tak jak poprzednio, przyjmiemy, że wartości $\gamma$ dla poszczególnych kanałów są znacznie mniejsze od 1, to wyrażenie (16) upraszcza się do postaci:

$$
\gamma_{e 1} \approx \frac{\left(\gamma_{2}+\gamma_{1}\right) q_{2}+\left(\gamma_{3}+\gamma_{1}\right) q_{3}+\gamma_{1} q_{1}}{q_{1}+q_{2}+q_{3}}
$$

Drugą kwestią, mocno ograniczającym praktyczne zastosowanie MDE, jest niejawne, aczkolwiek jasno wynikające z samego algorytmu dekompozycji, założenie, że sieć jest drzewem binarnym. Takie założenie wyklucza przypadki, kiedy węzeł łączy więcej niż dwa kanały dopływające.

Rozwiązaniem może być tutaj wprowadzenie w trakcie obliczeń pomocniczych kanałów fikcyjnych o zerowej długości, a zatem również zerowych wydatkach i zerowych parametrach strumienia intensywności uszkodzeń (rys. 3.).

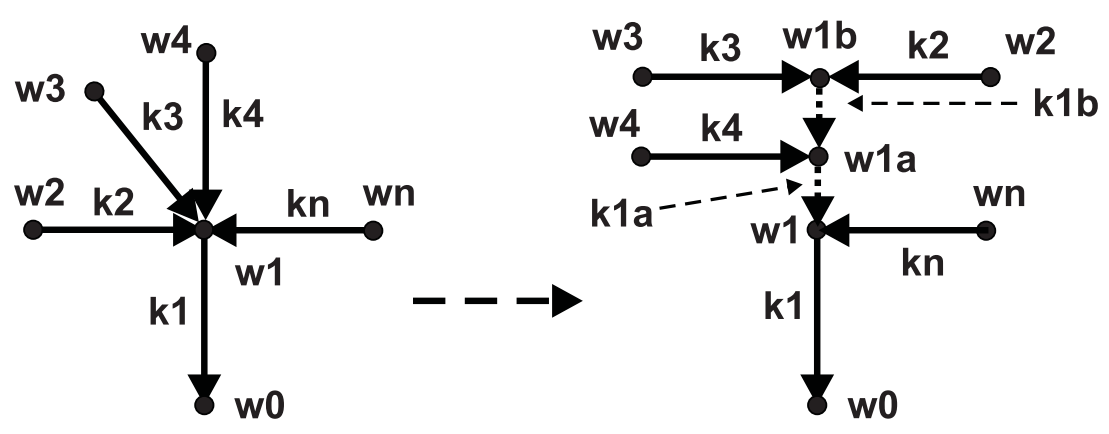

Rys. 3. Schemat zastąpienia węzła niebinarnego (w1) w drzewie drabiną węzłów binarnych (w1, w1a, w1b) i krawędzi o zerowej długości

Fig. 3. Replacement of a non-binary node (w1) in a tree with a binary nodes ladder (w1, W1A, W1B) and an edge of zero length

Zerowe wartości wydatków i strumieni intensywności uszkodzeń są logiczną konsekwencją zerowej długości kanału fikcyjnego. Problem stanowi wartość strumienia intensywności odnowy, a w konsekwencji wartość bezwymiarowego parametru $\gamma$. Biorąc jednak pod uwagę fizyczną interpretację tego parametru, przedstawioną $\mathrm{w}$ poprzednim rozdziale, możemy założyć, że również on przyjmuje wartość zerową. 
Zwinięcie dwóch pierwszych gałęzi, aż do kanału k1b, prowadzi do prostych wzorów na wielkości ekwiwalentne:

$$
\gamma_{e \mathrm{lb}}=\frac{\gamma_{2} q_{2}+\gamma_{3} q_{3}}{\left(1+\gamma_{3}\right) q_{2}+\left(1+\gamma_{2}\right) q_{3}}
$$

oraz

$$
Q_{e 1}=\frac{\gamma_{2} q_{2}+\gamma_{3} q_{3}}{1+\gamma_{2}+\gamma_{3}} T
$$

Oczywiście ekwiwalentny wydatek kanału k1b jest równy sumie wydatków kanałów do niego spływających, czyli $q_{2}$ i $q_{3}$.

Dalsze iteracje prowadzą do dosyć złożonych ścisłych wzorów na kolejne wartości $\gamma_{\mathrm{e}}$ i $Q_{\mathrm{e}}$. Oczywiście, nic nie stoi na przeszkodzie, aby zwijanie tego typu grafu dokonywać iteracyjnie, posługując się kolejnymi wielkościami ekwiwalentnymi. Wtedy obliczenia sprowadzają się do kolejnego wykorzystania zależności (18) i (19).

Posiłkując się jednak założeniem małych względem 1 wartości $\gamma$, możemy podać bardzo proste wzory przybliżone dla całości grafu:

$$
\gamma_{e 1} \approx \frac{\gamma_{2} q_{2}+\gamma_{3} q_{3}+\gamma_{4} q_{4}+\cdots+\gamma_{n} q_{n}}{q_{2}+q_{3}+q_{4}+\cdots+q_{n}}
$$

oraz

$$
Q_{e 1} \approx \gamma_{2} q_{2}+\gamma_{3} q_{3}+\gamma_{4} q_{4}+\cdots+\gamma_{n} q_{n}
$$

Pozostaje jeszcze rozpatrzenie przypadku, kiedy węzeł łączy jeden kanał doprowadzający ścieki i jeden kanał odprowadzający. Taki schemat zastąpimy układem Y-kształtnym, w którym drugi kanał doprowadzający ścieki (niech będzie to kanał nr k3) ma zerowy wydatek i zerowy parametr $\gamma$ (rys. 4.).
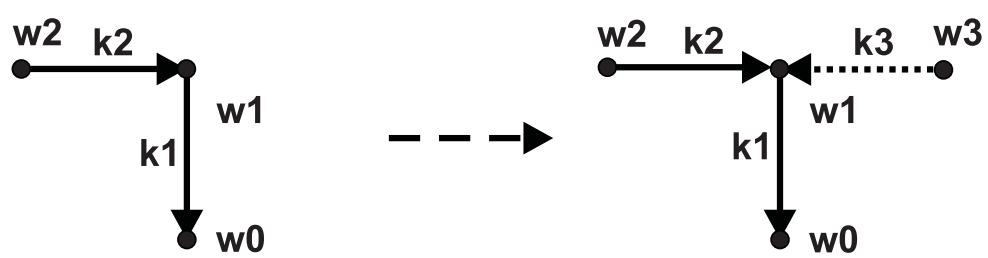

Rys. 4. Schemat zastąpienia węzła łączącego tylko 2 kanały (k1 i k2) strukturą Y-kształtną z kanałem $\mathrm{nr}$ k3 o zerowym wydatku i zerowym parametrze $\gamma$

Fig. 4. Replacement of a node connecting only 2 channels (k1 and k2) with a Y-shaped structure and the channel K3 of zero flow $(\gamma=0)$ 
Dla takiego układu wartość $\gamma_{\mathrm{el}}$ jest prostą konsekwencją równania (16):

$$
\gamma_{e 1}=\frac{\left(\gamma_{2}+\gamma_{1}\right) q_{2}+\gamma_{1} q_{1}}{q_{2}+\left(1+\gamma_{2}\right) q_{1}}
$$

natomiast wartość $Q$ bezpośrednio wynika z równania (13):

$$
Q=\frac{\left(\gamma_{2}+\gamma_{1}\right) q_{2}+\gamma_{1} q_{1}}{1+\gamma_{1}+\gamma_{2}} T
$$

przez proste podstawienie zerowych wartości $q_{3} \mathrm{i} \gamma_{3}$.

\section{Podsumowanie}

Porównując wzory (4) oraz (9) ze wzorami (13) oraz (16) dochodzimy do wniosku, że rezygnacja z założenia zerowego wydatku dla kanału odprowadzającego nie komplikuje znacząco wzorów na wartości ekwiwalentne parametrów $\gamma_{\mathrm{e}}$ i $Q_{\mathrm{e}}$, co przekonuje, że założenie to w pierwotnej wersji MDE było zbyt daleko idące.

W artykule pokazano również, że potrzeba, ze względu na algorytm dekompozycji, binarności drzewa grafu sieci jest pozorna i da się wyeliminować poprzez wprowadzenie kanałów fikcyjnych, o zerowym wydatku i zerowym strumieniu intensywności uszkodzeń, wszędzie tam, gdzie binarność ta nie jest zachowana. Pozostaje więc jedynie wymóg, aby sieć kanalizacyjna była grafem typu drzewo, co, ze względu na charakter pracy sieci grawitacyjnej, jest założeniem nie powodującym żadnych ograniczeń.

Przy takiej redukcji ograniczeń metoda dekompozycji i ekwiwalentowania Jermolina i Alieksjejewa okazuje się być wygodnym i przydatnym narzędziem do obliczeń parametrów $\gamma_{\mathrm{e}}$ i $Q_{\mathrm{e}}$.

\section{Literatura}

[1] Ermolin Ju. A., Alekseev M. I.: Metod dekompozicii i ekvivalentirovanija kanalizacionnoj seti. Vodosnabżenie i sanitarnaja technika No 11 s.51-57, 2012.

[2] Królikowska J.: Niezawodność funkcjonowania i bezpieczeństwa sieci kanalizacyjnej. Monografia 382. Wydawnictwa PK, Kraków 2010.

[3] Królikowska J.: Aplikacja metody grafu do szacowania niezawodności funkcjonowania sieci kanalizacyjnej. Materiały IX Międzynarodowej Konferencji Naukowo-Technicznej nt. „Zaopatrzenie w wodę, jakość i ochrona wód”, PoznańKołobrzeg 2010, s. 373-382.

[4] Królikowska J., Królikowski A.: Analiza porównawcza metod oceny niezawodności systemów usuwania i unieszkodliwiania ścieków, Instal 10/2008. 
[5] Królikowska J., Królikowski A.: Applying the dendrical scheme failure metod to swage drailing subsystem reliability evaluation. Environmental Engieering III. CRS Press Taylor and Francis Group. London 2010. s.191-195.

[6] Królikowska J., Królikowski A., Konior T.: Przegląd metod do oceny niezawodności działania sieci kanalizacyjnej. Mat. konf. „Praktyczne funkcjonowanie przedsiębiorstw wodociągowo-kanalizacyjnych w warunkach rosnących wymagań ekologicznych, ekonomicznych i społecznych", Bielsko-Biała 2013, s. 201-211.

[7] Kwietniewski M., Rak J.: Niezawodność infrastruktury wodociągowej i kanalizacyjnej w Polsce. Studia z Zakresu Inżynierii, nr 67. Polska Akademia Nauk, Warszawa 2010.

[8] Kwietniewski M., Podedworna J., Sozański M. (red.): Stan aktualny i kierunki rozwoju nauki w zakresie zaopatrzenia w wodę, usuwania ścieków i unieszkodliwiania osadów oraz gospodarki odpadami. Wydaw. Komitetu Inżynierii Lądowej i Wodnej PAN. Studia z Zakresu Inżynierii, nr 85. Warszawa 2014.

[9] Leśniewski M.: Ocena niezawodności systemu kanalizacji deszczowej dla potrzeb analizy ryzyka. Rozprawa doktorska. Wydawnictwa Politechniki Warszawskiej. Warszawa 2007.

[10] Pietrucha K., Rak J.: Oddziaływanie systemów kanalizacyjnych na wody odbiornika. Konferencja: I Konferencja "Walory przyrodniczo-historyczne pogórzy", s.109128, 2008.

[11] Rak J., Boryczko K.: Sposób oceny niezawodności operatora SZW metodą drzewa zdarzeń z możliwością poprawy popełnionego błędu. s.47-49, Wydawnictwo SIGMA-NOT SP. z o.o., Gaz, Woda i Technika Sanitarna, z.9, 2009.

\section{PROBLEMS WITH A PRACTICAL APPLICATION OF THE METHOD OF DECOMPOSITION AND EQUIVALENT}

\section{S u m m a r y}

The paper presents the method of decomposition and equivalent (MDE), proposed by Jermolin and Alieksjejew. The method helps to calculate reliability parameters of the sewage system in a much simpler and less burdensome way, if compared to other methods such as: a complete review method, a method of analytical formulas, a method of failure frequency or a graph method. In the method presented in [1], the authors assumed that only the channels that constitute the edges of the graph tipped with leaves, or external network channels have a non-zero discharge. Such an assumption limits its practical application. Another issue, that strongly limits practical applications of MDE is the assumption, implicit but clearly resulting from the decomposition algorithm, that the network has a form of a binary tree. Such an assumption excludes cases when a node connects more than two inflow channels. The study presents solutions to these problems (constraints).

Keywords: reliability, sewage networks, graph, decomposition, equivalents, failure

Przestano do redakcji: $30.05 .2015 \mathrm{r}$.

Przyjęto do druku: 30.10.2015 r.

DOI: $10.7862 / \mathrm{rb} .2015 .109$ 